\title{
Circadian variations of acute toxicity and blood and brain concentrations of inhaled toluene in rats
}

\author{
I Harabuchi, R Kishi, T Ikeda, H Kiyosawa, H Miyake
}

\begin{abstract}
To investigate circadian variations in the acute toxicity of toluene, rats were exposed to it (2000 ppm or $4000 \mathrm{ppm}$ ) both in the dark (the animals' active phase) and the light (the inactive phase) for 4 hours. The performance decrements of rats were greater in the light phase than in the dark phase in all time zones of exposure to toluene. In the dark phase, the performance recovered almost to that preexposure, whereas a significant delay of recovery was noted in the light phase. The differences in the number of lever presses between exposure to $2000 \mathrm{ppm}$ toluene and control (air) exposure were also greater in the light phase than in the dark phase. Significant differences according to the time of exposure were also found in toluene concentrations in blood and the brain. Both blood and brain concentrations in the light phase were higher than those in the dark phase at four hours after exposure to $2000 \mathrm{ppm}$ toluene or at two hours after exposure to $4000 \mathrm{ppm}$ toluene. These results suggest that there was a significant difference in circadian susceptibility after exposure to toluene, which might be caused by circadian differences in the pharmocokinetics of toluene in the light and dark phases.
\end{abstract}

(British Journal of Industrial Medicine 1993;50:280-286)

It is well known that many functions of the human body, including thermoregulation, sleep wake cycles, and renal function, have strong periodic characteristics that change over a cycle of roughly 24 hours (circadian rhythm). ${ }^{1}$ There are also many reports indicating that pharmacological effects vary according to the time of drug administration during the day. ${ }^{2}$ For instance, some reports show that circadian rhythms influence the effects of anaesthetics or sleeping drugs such as pentobarbital, hexobarbital, ${ }^{34}$ and ethanol. $^{5}$

Department of Public Health; Sapporo Medical College, Japan

I Harabuchi, R Kishi, T Ikeda, H Kiyosawa, H Miyake
According to labour statistics in the United States, about $18 \%$ of the labour force has to work in shift systems under unsocial and unphysiological conditions. ${ }^{6}$ In many industrialised countries over the past two decades a number of enterprises that require continuous process operations have adopted unusual workshifts. Therefore, it is probable that the time of exposure to chemical substances differs depending on the actual working conditions. So far only a few reports have been made on the adverse effects of toxic substances on living organisms exposed to such chemicals at different times of day. ${ }^{7-11}$ In many previous studies of the influence of circadian rhythms on pharmacological effects, the main concerns were the lethality at high concentrations such as the median lethal dose $\left(\mathrm{LD}_{50}\right)^{1}$ or the duration of the effects of sedatives. ${ }^{12}{ }^{13} \mathrm{It}$ is also important to study the circadian difference in toxicity at concentrations lower than the $\mathrm{LD}_{50}$ using techniques such as operant conditioning behaviour, because behavioural performance and fatigue have a close relation with the health condition of night workers. ${ }^{146}$

The aim of the present study was to show, firstly, the circadian variations in susceptibility to the acute behavioural toxicity of toluene, a widely used organic solvent, in rats exposed at different times; secondly, to investigate how this correlated with toluene concentrations in the blood and brain, because the behavioural effects of toluene on the central nervous system are closely related to such increases. ${ }^{15}$ Chronobiologically there are many circadian differences in physiological functions that affect the pharmacokinetics of toluene under dark and light in the environment, for example, metabolising enzyme activity in the liver and renal function in the excretion of solvent metabolites. ${ }^{16} 17$

\section{Methods}

ANIMALS AND ILLUMINATION REGIMENS

A total of 112 male Wistar rats were used for the behavioural test. Because rats are nocturnal animals, they were kept under inverted dark light conditions (dark phase: 0900-2100; light phase: 2100-0900) beginning at four weeks of age to accommodate them to this illumination regimen. To keep the active 
Table 1 Order of exposure to toluene

\begin{tabular}{|c|c|c|c|c|}
\hline & 1st exposure & 2nd exposure & 3rd exposure & 4th exposure \\
\hline Group 1 & $4000 \mathrm{ppm}$ & $4000 \mathrm{ppm}$ & $2000 \mathrm{ppm}$ & $2000 \mathrm{ppm}$ \\
\hline Group 2 & $\begin{array}{l}\text { (in the light phase) } \\
4000 \text { ppm } \\
\text { (in the dark phase) }\end{array}$ & $\begin{array}{l}\text { (1n the dark phase) } \\
4000 \text { ppm } \\
\text { (in the light phase) }\end{array}$ & $\begin{array}{l}\text { (1n the light phase) } \\
2000 \text { ppm } \\
\text { (in the dark phase) }\end{array}$ & $\begin{array}{l}\text { (n the dark phase) } \\
2000 \mathrm{ppm} \\
\text { (in the light phase) }\end{array}$ \\
\hline
\end{tabular}

phase of the rats within a constant time zone, the feeding time was fixed at 0900 , the beginning of the dark phase. Water was given freely. Body weight was kept constant to eliminate a difference in fat volume during the exposure experiments.

\section{BEHAVIOURAL PROCEDURE}

The shock avoidance response (fixed negative interval schedule with a sound signal $)^{18}$ was used to establish a behavioural baseline for the observation of behavioural changes after exposure to toluene. The animals were trained for one hour every two days with a reinforcement schedule having a 10 second shock to shock interval, a sound signal being presented for five seconds before every electric shock. Under this schedule, the animals could avoid an electric shock if they pressed a lever when the sound signal was on. The apparatus used in the behavioural test consisted of Skinner boxes that were placed in a gas chamber with programming and recording equipment. A shock generator and scrambler (BRS/ LVE) were used to deliver a $2.5 \mathrm{~mA} \mathrm{DC}$ shock to the grid floor of each Skinner box for 0.3 seconds. The experimental contingencies were controlled by a Sord M23 microcomputer and related peripheral apparatus.

The behavioural baseline was established in the animals after 10 to 15 training sessions. After this, 16 rats whose avoidance rate was successful in over $85 \%$ of the trials were selected and exposed to toluene. The 16 rats were assigned to two groups, each with eight rats, in such a manner that there was no difference in the mean number of avoidance responses between the two groups. For group 1, the first exposure was given in the light phase and the second exposure in the dark phase. By contrast, the first exposure was given in the dark phase for group 2 and the second exposure in the light phase. These procedures were carried out to minimise any differences occurring as a result of the sequence of exposure in the light and dark phases (table 1).

\section{TOLUENE EXPOSURE AND TIME OF BEHAVIOURAL TESTS}

Static exposures were conducted in two exposure chambers described previously. ${ }^{19}$ The rats were exposed to toluene for four hours at $4000 \mathrm{ppm}$ and
Schedule of behavioural test

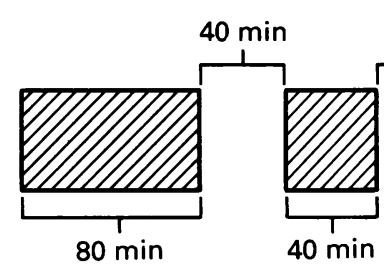

$20 \mathrm{~min}$

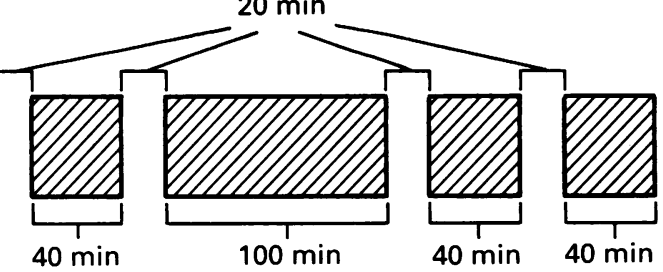

Exposure
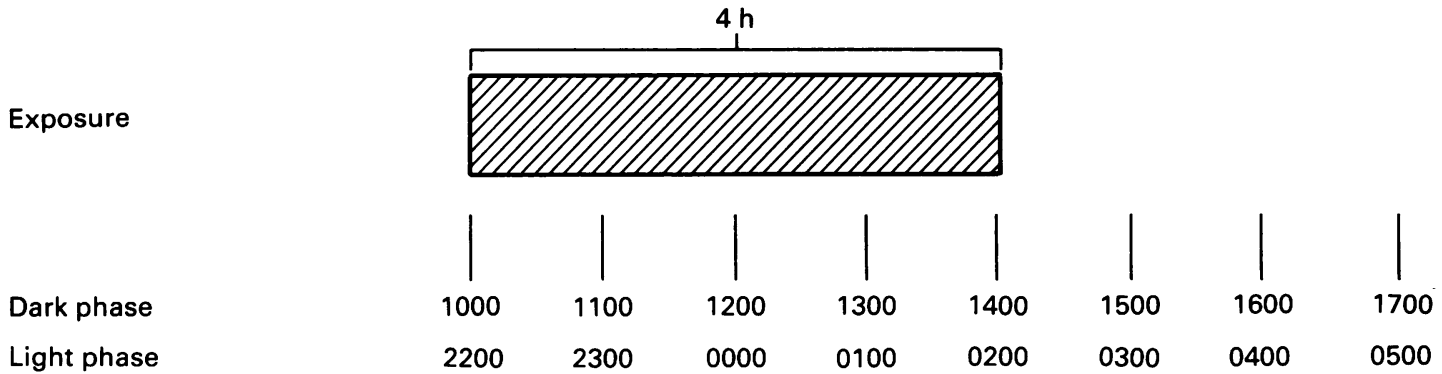

Clock hour

Figure 1 Time schedule of behavioural tests and exposure. 
$2000 \mathrm{ppm}$. Concentration of toluene vapour was determined with a Shimazu 4 BPTF gas chromatograph. Figure 1 shows the time schedule of the experiment. The time of exposure was set at 1000 1400 in the dark phase and 2200-0200 in the light phase. At 40 minutes before each exposure the preexposure level was measured to exclude the warming up effect and to check the performance of the rats on the day of experiment. Then the rats were continuously exposed to toluene. After four hours of exposure, toluene was exhausted from the chamber, and the process of recovery was carefully watched for the next three hours.

After a time interval of more than one week, the next behavioural experiment was conducted to check the stability of the base line and the rats were subjected to the second exposure. After an interval of another week, the rats were exposed to $2000 \mathrm{ppm}$ of toluene for four hours in the dark or light phase. The third and the fourth exposures were performed with the procedure described above. The numbers of lever presses and shocks received per 20 minute period for each time zone for both light and dark phases were adopted as the behavioural test parameters.

\section{MEASUREMENT OF TOLUENE CONCENTRATIONS IN BLOOD AND BRAIN}

Toluene concentrations in rat blood and brain were quantitatively determined at $\mathbf{4 0}$ minutes, two hours, and four hours after the start of exposure and at 30 minutes after the end of exposure. Six rats were used for each time schedule in both the light and the dark phases. Accordingly, a total of 96 rats equivalent in weight and age to the animals of the behavioural experiment were used for the measurement of toluene concentrations in blood and brain. The rats were killed and blood was dispensed into an all glass container with heparin. The brain was then removed. The concentrations of toluene in blood and brain were determined by the modified gas chromatographic equilibration method of Sato et al. ${ }^{20}$

\section{STATISTICAL ANALYSIS}

The differential effects of toluene between the dark phase exposure and the light phase exposure were evaluated by comparing the performance of rats during and after their own performance under a dummy exposure in air. The statistical significance of experimental results was determined by a two or three way analysis of variance in which the exposure effects, time effects, and the differences within the 16 individual rats were included as the two or three factors. For the comparison of toluene concentrations in blood and brain, Student's $t$ test was used to compare the concentration under the light and dark phases at 40 minutes, two hours, and four hours after the start of exposure and at 30 minutes after the end of exposure.

\section{Results}

\section{BODY WEIGHT}

For the 16 rats used in the behavioural test, the average body weight (SD) at the start of the learning performance experiment was 408.0 (29.9) $\mathrm{g}$ for the eight rats in group 1 and $401.4(50.0) \mathrm{g}$ for those in group 2. Neither apparent toxicological signs nor an increase or decrease in body weight were found during the experiments.

\section{BASELINE LEVEL OF PERFORMANCE BEFORE EXPOSURE TO TOLUENE}

Before the exposure, 20-40 minutes of warming up were required to reach a constant value for the number of avoidances in both light and dark phases. Thereafter, the number of avoidances of each rat stabilised, being more than 100 in 120 trials at the end of the experiment, and no difference was found between the light phase and the dark phase (fig 2A). In the number of lever presses, the mean (SD) of the number of lever presses for every 20 minutes was $181.5(11.4)$ in the dark phase and $176.0(13.7)$ in the light phase. The mean number of lever presses was slightly increased in the dark phase, but no significant difference was found between the two phases (fig 2B).

\section{AVOIDANCE PERFORMANCE WITH EXPOSURE TO 4000 PPM TOLUENE}

A significant decrease in the avoidance response was noted soon after the start of exposure compared with
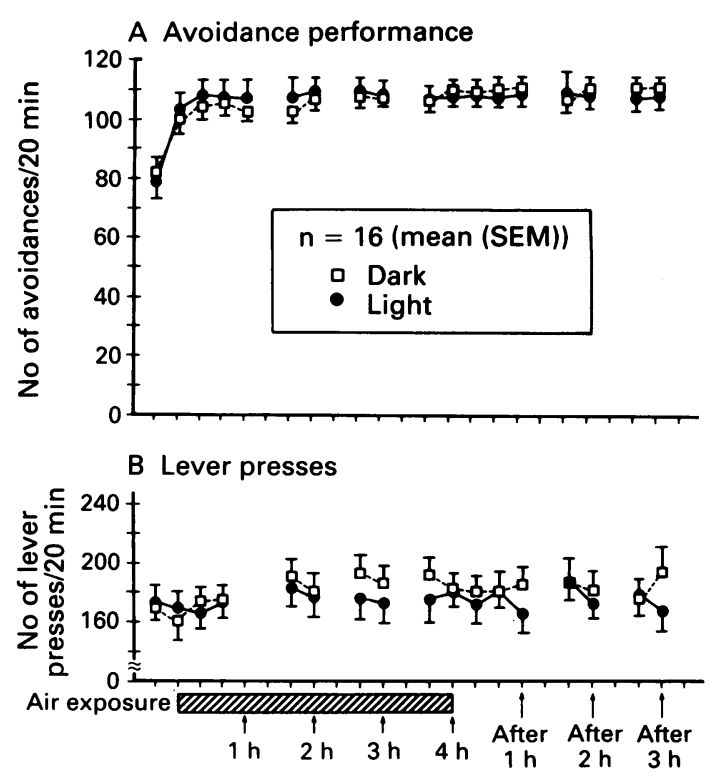

Figure 2 Baseline performance of the avoidance response $(A)$ and the number of lever presses $(B)$ per 20 minutes in rats in air without toluene exposure in the dark phase and light phase. 

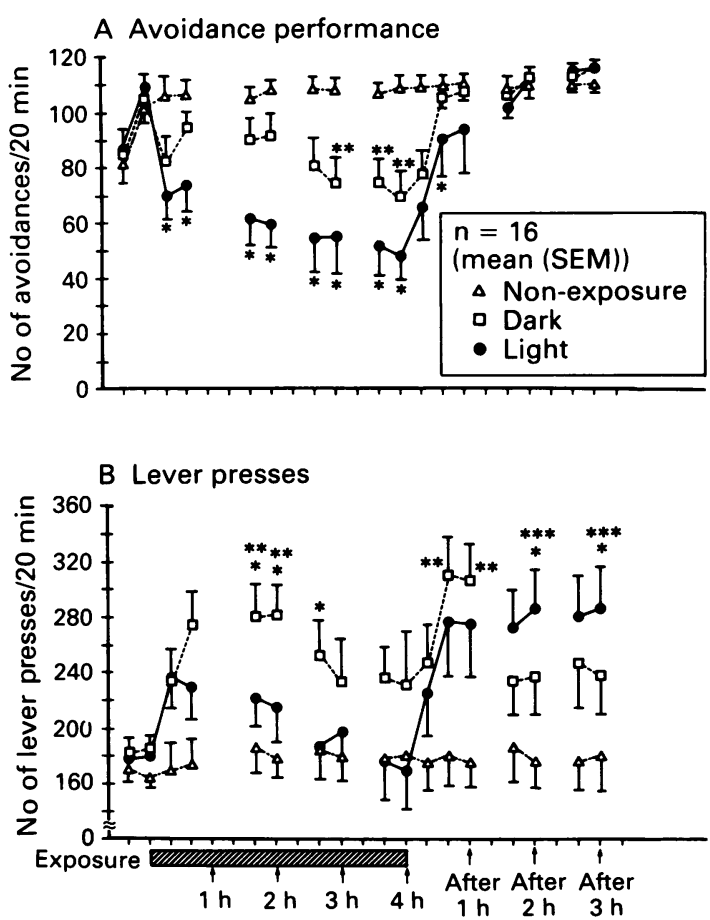

Figure 3 Effects of exposure to 4000 ppm toluene on the avoidance response $(A)$ and the number of lever presses ( $B$ ) per 20 minutes in rats.

the value before the exposure in both the light and dark phases. Also, there was a significant difference in the decrements of avoidance performance between the exposure in the dark phase and that in the light phase (fig 3A). The mean (SD) of the number of avoidances for every 20 minutes in the light phase and in the dark phase respectively for all 16 rats was: (1) before the exposure 109.0 (1.7) and 104.9 (2.3); (2) 20 minutes after exposure $69.8(6.3)$ and $82.5(6.2)$; (3) two hours after exposure 59.4 (9.4) and $91 \cdot 6(5 \cdot 1)$; (4) three hours after exposure $54 \cdot 6(9 \cdot 3)$ and $74 \cdot 2$ $(8 \cdot 6)$; (5) four hours after exposure $47 \cdot 6(8 \cdot 7)$ and $69 \cdot 1$ (7.6); (6) 20-40 minutes after the end of exposure $89 \cdot 8(7 \cdot 1)$ and $104 \cdot 4(3 \cdot 7)$. In the dark phase exposure to toluene, the performance level recovered roughly to the pre-exposure level, whereas a significant delay of recovery was noted in the light phase.

As shown in fig 3B, a significant increase in the number of lever presses was seen at two hours and three hours after the exposure in the dark phase. After the end of exposure the number of lever presses in the dark phase gradually decreased to almost the level of pre-exposure. By contrast, a significant delay of recovery to the pre-exposure level was noted in the light phase at two hours and three hours after the end of exposure.
PERFORMANCE CHANGES WITH EXPOSURE TO 2000 PPM TOLUENE

As shown in fig 4B, after the start of exposure to toluene, the number of lever presses was significantly increased compared with the baseline level before the exposure. The differences in the number of lever presses between exposure to toluene and control (air) exposure was greater during exposure in the light phase than during the exposure in the dark phase. No significant difference in the number of avoidances was noted throughout all time zones for both light and dark phases (fig $4 \mathrm{~A}$ ).

TOLUENE CONCENTRATIONS IN BLOOD AND BRAIN

Tables 2 and 3 show the toluene concentration in the blood and brain after exposure to $4000 \mathrm{ppm}$ and $2000 \mathrm{ppm}$ toluene. There were statistically significant differences between light phase and dark phase blood and brain concentrations at two hours after exposure to $4000 \mathrm{ppm}$ and at four hours after exposure to $2000 \mathrm{ppm}$. Circadian differences in concentrations in both blood and brain toluene were found at four hours after exposure to $2000 \mathrm{ppm}$ toluene and at two hours after exposure to $4000 \mathrm{ppm}$.

Figure 5 shows the relation between the number of avoidances and the blood toluene concentrations under $4000 \mathrm{ppm}$ toluene exposure for the dark $v$ light phase. The blood toluene concentration increased almost linearly after the exposure, which correlated well with the behavioural decrements of performances of rats per 20 minutes. The concentrations of blood toluene in the light phase were higher than

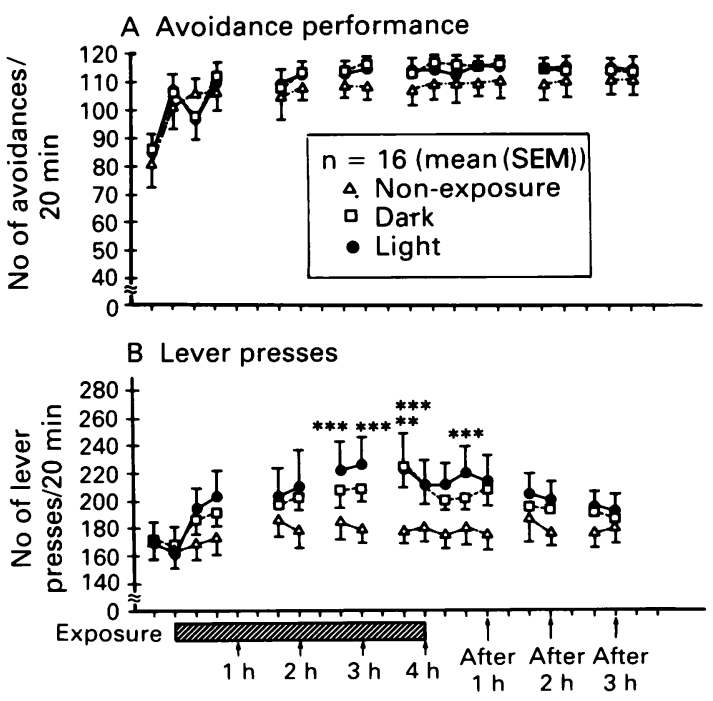

Figure 4 Effects of exposure to 2000 ppm toluene on the avoidance response $(A)$ and the number of lever presses ( $B$ ) per 20 minutes in rats. 
Table 2 Blood concentration ( $\mathrm{mg} / \mathrm{dl}$ ) of toluene after 4000 ppm and 2000 ppm exposure in the dark phase and light phase

\begin{tabular}{|c|c|c|c|c|}
\hline & $\begin{array}{l}40 \text { minutes after } \\
\text { exposure } \\
\text { Mean }(S D)\end{array}$ & $\begin{array}{l}2 \text { hours after } \\
\text { exposure } \\
\text { Mean (SD) }\end{array}$ & $\begin{array}{l}4 \text { hours after } \\
\text { exposure } \\
\text { Mean (SD) }\end{array}$ & $\begin{array}{l}30 \text { minutes after the } \\
\text { end of exposure } \\
\text { Mean (SD) }\end{array}$ \\
\hline $\begin{array}{l}2000 \text { ppm }(n=6) \\
\text { Light phase } \\
\text { Dark phase }\end{array}$ & $\begin{array}{l}49 \cdot 1(5 \cdot 6) \\
44 \cdot 5(5 \cdot 8)\end{array}$ & $\begin{array}{l}61 \cdot 1(4 \cdot 7) \\
64 \cdot 4(10 \cdot 5)\end{array}$ & $\begin{array}{l}97 \cdot 0(8.4)^{\star} \\
69.5(9.9)\end{array}$ & $\begin{array}{l}72 \cdot 5(13 \cdot 8)^{\star} \\
51 \cdot 2(6 \cdot 0)\end{array}$ \\
\hline
\end{tabular}

* Significantly different from dark phase.

those of the dark phase at the same periods after exposure.

\section{Discussion}

Unexpectedly, under the non-exposure conditions (air exposure), lever pressing performance in the light phase was almost the same as in the dark phase. This was probably because such a strong stimulation (a $2.5 \mathrm{~mA}$ electric shock) was given to the rats that their performance in the light phase was maintained at the same level as in the active phase. During the exposure to $4000 \mathrm{ppm}$ toluene the number of: avoidances both in the dark phase and light phase decreased, whereas the number of lever presses increased to nearly two to threefold that of nonexposure. Also, during exposure to $2000 \mathrm{ppm}$, the number of lever presses was increased, although there were no differences in the avoidance response: rates. Such behavioural changes showed that higher concentrations of toluene (generally 1000 to 4000 $\mathrm{ppm}$ ) caused performance decrement of avoidance responses with abnormal excitement of the central nervous system in rats after the increases in blood and brain concentrations: this agrees well with previous reports. ${ }^{15} 21$

In the present study we investigated whether there was any circadian difference in the susceptibility of rats exposed to toluene during the dark phase and the light phase under exposures to $4000 \mathrm{ppm}$ and $2000 \mathrm{ppm}$ toluene, concentrations about a half to a quarter of the $\mathrm{LD}_{50}(8800 \mathrm{ppm})$ of exposure to toluene. ${ }^{22}$ Exposure to toluene seems to be an appropriate model for the chronopharmacological study of organic solvents, as it is absorbed quickly by inhalation exposure, metabolised, and excreted via the urine within several hours. We found that the adverse effects of toluene in the conditioned avoidance performance of rats were different in the light phase and dark phase. Both the decreased rate of the number of avoidances during exposure to 4000 ppm toluene and the increased rate of lever pressing during exposure to $2000 \mathrm{ppm}$ in the light phase were significantly higher than those in the dark phases. A significant difference according to the time of exposure was also found in the concentrations in blood and brain.

The mechanism accounting for circadian differences in the pharmacological effects of chemicals has not yet been thoroughly investigated, but two reasons may cause such differences in the susceptibility to drugs that affect the central nervous system. The first is the circadian difference in pharmacokinetics of the drugs brought about by the circadian difference in activity of enzymes metabolising the drug. The second is presumed to be a change in pharmacological effects, influenced by the circadian rhythm of brain amine metabolism, because effects of some neuroleptic drugs were synchronised with the circadian differences of synthesis and the release of brain amines. ${ }^{2324}$ Soliman and Walker reported a distinct circadian difference in ethanol concentration in blood according to the time of administration, which might be why the lethal rate and the duration of sedation in the light phase and dark phase were different ${ }^{25} \mathrm{On}$ the other hand, Nagayama et al reported that in the case of the antipsychotic tetrabenazine no difference was

Table 3 Brain concentration ( $\mathrm{mg} / \mathrm{dl}$ ) of toluene after $4000 \mathrm{ppm}$ and $2000 \mathrm{ppm}$ exposure in the dark phase and light phase

\begin{tabular}{|c|c|c|c|c|}
\hline & $\begin{array}{l}40 \text { minutes after } \\
\text { exposure } \\
\text { Mean (SD) }\end{array}$ & $\begin{array}{l}2 \text { hours after } \\
\text { exposure } \\
\text { Mean (SD) }\end{array}$ & $\begin{array}{l}4 \text { hours after } \\
\text { exposure } \\
\text { Mean (SD) }\end{array}$ & $\begin{array}{l}30 \text { minutes after the } \\
\text { end of exposure } \\
\text { Mean }(S D)\end{array}$ \\
\hline $\begin{array}{l}4000 \text { ppm }(n=6) \\
\text { Light phase } \\
\text { Dark phase }\end{array}$ & $\begin{array}{r}119.9(18.7) \\
95 \cdot 1(16.0)\end{array}$ & $\begin{array}{l}146.0(13.4)^{\star} \\
127.6(9.6)\end{array}$ & $\begin{array}{l}155 \cdot 2(41 \cdot 0) \\
144 \cdot 4(15 \cdot 4)\end{array}$ & $\begin{array}{l}99.9(21.3) \\
99.0(10.0)\end{array}$ \\
\hline $\begin{array}{l}2000 \text { ppm }(\mathrm{n}=6) \\
\text { Light phase } \\
\text { Dark phase }\end{array}$ & $\begin{array}{l}62 \cdot 3(4 \cdot 6) \\
57 \cdot 2(3.9)\end{array}$ & $\begin{array}{l}70 \cdot 4(6 \cdot 3) \\
63.6(6.3)\end{array}$ & $\begin{array}{c}101.5(11.7)^{\star} \\
69.9(6.5)\end{array}$ & $\begin{array}{l}75.6(9.9)^{\star} \\
43.0(4.2)\end{array}$ \\
\hline
\end{tabular}

^Significantly different from dark phase. 


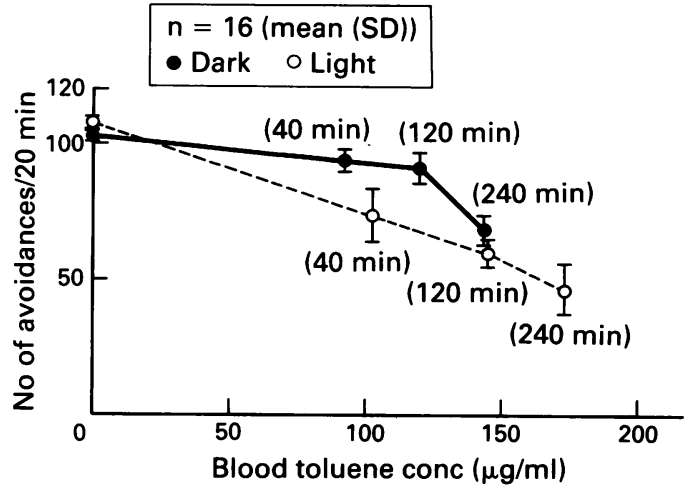

Figure 5 Relation between number of avoidances and concentrations of toluene in blood during exposure to 4000 ppm toluene in the dark $v$ light phase. Mean (SD) of avoidance responses in 16 rats at various exposure times (parentheses) are plotted against mean toluene concentrations in blood at corresponding times.

found in the blood concentration of tetrabenazine according to the time of administration in the light phase and dark phase, whereas a large difference was noted in the duration of the effect of sedation, ${ }^{26}$ suggesting that the circadian difference of the sedative effects might beinfluenced by the circadian differences of the activity of brain amines. In the present study, the circadian difference of susceptibility to acute exposure to toluene may not be related to the circadian fluctuation of monoamine synthesis and release in the brain, because it was reported that the concentrations of brain monoamines were not changed in an experiment with a single inhaled exposure in rats, although they were changed under chronic toluene exposure.

It has also been reported that some of the metabolic enzymes in the liver have a 24 hour daily rhythm of activity, being synchronised with light dark regimens in the environment. ${ }^{27}$ For example, Nair and Casper, ${ }^{19}$ and Holsclaw et al ${ }^{18}$ reported that the activity of hexobarbital oxidase was high in the dark phase and low in the light phase. On the other hand, it is well known that $80 \%$ of inhaled toluene is also metabolised via the process of oxidation of the methyl radical in the side chain by the mixed function oxidase in liver..$^{28}$ Therefore, it is probable that the rate of metabolism of toluene differs with the time of exposure because of the circadian rhythm of such oxidase activity. In the present study toluene concentrations in both blood and brain were significantly higher in the light phase than in the dark phase after $4000 \mathrm{ppm}$ two hour exposure and $2000 \mathrm{ppm}$ four hour exposure. These results suggest that the circadian rhythm of enzymatic activity is one of the causes of circadian differences in the susceptibility to toxicity after exposure to toluene..$^{29} 30$
The feeding time of the animals, which is usually in the humans' or animals' active phase, may play another important part in the circadian difference of toxicity. Recently biochemical and pathological studies indicated that hepatotoxicity in rats given an organic solvent was enhanced by food deprivation. ${ }^{31}$ In the present study we fixed the time of feeding for all animals at 0900 , the beginning of the dark (animals' active) phase, to avoid such a confounding effect by the feeding schedule.

Further studies to clarify the degree of circadian difference of toxicity in rats exposed to low concentrations of toluene and the mechanism of circadian variation of organic solvents will be needed because threshold limit values of industrial chemicals are considered only for eight hour exposure in the active phase of the human 24 hour circadian variation. Nevertheless, more and more shift workers are engaged in irregular work schedules in modern industrialised countries. Exposure to other solvents may also exert different biological effects according to the time of exposure.

This research was supported in part by a grant in aid from the Japanese Ministry of Education, Science, and Culture.

Requests for reprints to: Reiko Kishi, $\mathrm{MD}, \mathrm{PhD}$, Department of Public Health Sapporo Medical College, Minami-1, Nishi-17, Chuou-Ku, Sapporo 060, Japan.

1 Hause E, Halberg F. The circadian time structure. In: Sheving LE, Halberg F, eds. Chronbiology: The principles and applications to shift schedules. Rockville: Sijthoff and Noordhoff, 1980:47-94.

2 Moore-Ede MC, Sultzman FM, Fuller CA. Medical implications of circadian rhythmicity. In: The clocks that time us. Cambridge, Mass: Harvard University Press, 1982:319-78.

3 Matthews JH, Marte E, Halberg F. A circadian susceptibilityresistance cycle to fluothane in male $\mathbf{B}$ mice. Canadian Anaesthetists Society Journal 1964;11:280-90.

4 Nelson W, Halberg F. An evaluation of time-dependence in susceptibility of mice to pentobarbital injection. Neuropharmacology 1973;12:509-24.

5 Deimling MJ, Schnell RC. Circadian rhythms in the biological response and disposition of ethanol in the mouse. $J$ Pharmacol Exp Ther 1980;213:1-8.

6 Rutenfranz J, Knauth P, Shift work. In: Zenz C, ed. Occupational medicine, principles and practical applications. Chicago: Year Book Medical Publishers Inc, 1988:1087-95.

7 Fatranska M, Vargova M, Rosival L, Batora V, Nemeth S, Janekova D. Circadian susceptibility rhythms to some organophosphate compounds in the rat. Chronobiologia 1978;5: 39-44.

8 Desgagne $\mathrm{M}$, Belanger PM. Chronotoxicity of styrene in rats. Annual Review of Chronopharmacology 1986;3:103-6.

9 Desgane $\mathbf{M}$, Boutet $\mathbf{M}$, Belanger PM. The mechanism of the chronohepato-toxicity of chloroform in rat: Correlation between binding to hepatic subellular fractions and histological changes. Annual Review of Chronopharmacoloty 1988;5:235-8.

10 Motohashi Y, Kawakami T, Miyazaki Y, Takano T, Ekataksin W. Circadian variations in trichloroethylene toxicity under a 12:12 hr light-dark cycle and their alterations under constant darkness in rats. Toxicol Appl Pharmacol 1990;104:139-48.

11 Motohashi Y, Miyazaki Y. Time-dependent effect of trichloroethylene on motor activity in rats. Chronobiol Int 1990;7: 193-201. 
12 Munson ES, Martucci RW, Smith RE. Circadian variation in anesthetic requirements and toxicity in rats. Anesthesiology 1970;32:507-14.

13 Sheving LE, Vedral DF, Pauly JE. A circadian susceptibility rhythm in rats to pentobarbital sodium. Anat $\operatorname{Rec} 1968$; 160:741-50.

14 Bjerner B, Holm A, Swensson A. Diurnal variation in mental performance. A study of three-shift workers. $\mathrm{Br} J$ Ind $\mathrm{Med}$ 1955;12:103-10.

15 Kishi R, Harabuchi I, Ikeda T, Yokota H, Miyake H. Neurobehavioural effects and pharmacokinetics of toluene in rats and their relevance to man. Br J Ind Med 1988;45:396-408.

16 Holsclaw TL, Miya TS, Bousquet WS. Circadian rhythm in drug metabolism in the mouse. $J$ Pharmacol Exp Ther 1975; 195:320-32.

17 Nair V, Casper R. The influence of light on daily rhythm in hepatic drug metabolizing enzyme in the rat. Life Sci 1969; 8:1291-8.

18 Ferster C, Skinner BF. Schedules of reinforcement. New York: Appleton Century Crofts, 1957.

19 Miyake H, Ikeda T, Maehara N, Harabuchi I, Kishi R, Yokota H. Slow learning in rats due to long-term inhalation of toluene. Neurobehavioural Toxicology and Teratology 1983; 5:541-8.

20 Sato A, Nakajima T. Determination of benzene and toluene in blood by means of a syringe-equilibration method using a small amount of blood. Br J Ind Med 1975;32:210-4.

21 Krivanek N, Mullin LS. Comparison of conditioned avoidance and unconditioned reflex tests in rats exposed by inhalation to carbon monoxide, 1,1,1-trichloroethane, toluene or ethanol Toxicol Appl Pharmacol 1978;45:357.

22 Carpenter CP, Geary DL Jr, Myers RC, Nachreiner DJ, Sullivan LJ, King JM. Petroleum hydrocarbon toxicity studies. XIII. Animal and human response to vapors of toluene concentrate. Toxicol Appl Pharmacol 1976;36:473-90.

23 Black IB, Parker L, Axelrod J. A daily rhythm in the rate of depletion of brain norepinephrine by reserpine. Biochemical Pharmacology 1969;18:2688-91.

24 Nagayama H, Takagi A, Sakurai Y, Yoshimoto S, Nishiwaki K, Tateishi R. Chronobiological study of neuroleptics. III. Circadian rhythm of brain susceptibility to haloperidol. Psychyopharmacology 1979;63:131-5.

25 Soliman KFA, Walker CA. Diurnal rhythm of ethanol metabolism in the rat. Experientia 1979;35:808-9.

26 Nagayama H, Takagi A, Tateishi T, Takahashi R. Circadian susceptibility rhythm to a neuroleptic: tetrabenazine. Psychopharmacology 1977;55:61-6.

27 Radialawski FM, Bousquet WF. Daily rhythmic variation in hepatic drug metabolism in the rat and mouse. J Pharmacol Exp Ther 1968;163:229-38.

28 Williams RT. The metabolism of aromatic hydrocarbons. In: Detoxication mechanisms: the metabolism and detoxication of drugs, toxic substances, and other organic compounds. 2nd ed. New York: John Wiley, 1959:188-236.

29 Yamawaki S, Sarai K. Effect of toluene inhalation on locomotor activity and brain catecholamine levels in rats. Japanese Journal of Psychopharmacology 1982;2:57-9.

30 von Euler G, Fuxe K, Hansson T, et al. Effect of chronic toluene exposure on central monoamine and peptide receptors and their interactions in the adult male rat. Toxicology 1988 ; 52:103-26.

31 Ikatsu H, Okino T, Nakajima T. Ethanol and food deprivation induced enhancement of hepatotoxicity in rats given carbon tetrachloride at low concentration. $B r J$ Ind 1991;48:636-42.

Accepted 29 June 1992 